\title{
Effectiveness and Dose of Carvedilol Therapy in Children with Dilated Cardiomyopathy: A Prospective Randomized Double-Blinded Trial
}

\author{
Zeinab S. Seliem ${ }^{1}$, Sonia A. El Saiedi' ${ }^{1}$, Reem I. Esmail ${ }^{1}$, Rania M. H. El Kaffas ${ }^{1}$, \\ Mohamed Meabed ${ }^{2}$, Baher M. Hanna ${ }^{1 *}$ \\ ${ }^{1}$ Department of Pediatrics, Faculty of Medicine, Cairo University, Egypt; \\ zeinabseliem14@yahoo.com,myheartclinic@windowslive.com, esmail_reem@yahoo.com, \\ raniaelkaffas@yahoo.com, baherhanna@gmail.com \\ 2 Department of Pediatrics, Faculty of Medicine, Beni-Suef University, Egypt; \\ m1hmeabed@yahoo.com \\ * Correspondence: baherhanna@gmail.com \\ Received: 22/2/2021; Accepted: 25/5/2021; Published online: 25/6/2021.
}

\begin{abstract}
:
Background: The efficacy and safety of the beta blocker carvedilol in pediatric patients with chronic heart failure (CHF) has not been fully established till now.

Aim of the Work: To assess the role of carvedilol in the treatment of children with dilated cardiomyopathy, to demonstrate its efficacy, tolerability and determine the least effective dose.

Patients and Methods: We conducted a double-blind, placebo-controlled study of 53 children with dilated cardiomyopathy (DCM). Patients were randomly assigned to receive either placebo (26 patients) or carvedilol (27 patients) added to the standard CHF therapy that consists of angiotensin-converting-enzyme inhibitor and diuretics. The carvedilol group was further subdivided into 2 groups according to the received dose of carvedilol. Subgroup I (11 cases) received carvedilol dose of 0.01-0.09 $\mathrm{mg} / \mathrm{kg} /$ day and subgroup II (16 cases) received carvedilol with dose increments every 2 weeks from $0.01-0.2 \mathrm{mg} / \mathrm{kg} / \mathrm{day}$. All patients were followed up for four months after reaching the target dose.

Results: The end results of the study showed that there was a significant improvement in Ross heart failure class, fractional shortening (FS), left ventricle end systolic dimension (LVESD) and left ventricle end diastolic dimension (LVEDD) in patients of the study group which was not achieved in the control group. On the other hand there was no statistically significant difference between sub groups I and II regarding the end point. Carvidolol was well tolerated, with no side effects or drug interaction reported.

Conclusion: Addition of carvedilol to standard anti-failure therapy is of beneficial effect and is well tolerated in children with CHF on top of DCM. There may be no need for carvedilol dose up- titration at least for the first months of treatment.
\end{abstract}

Level of Evidence of Study: IIA (1).

Keywords: Carvedilol; heart failure; cardiomyopathy; pediatric

Abbreviations: ACE: angiotensin-converting enzyme; CHF: chronic heart failure; DCM: dilated cardiomyopathy; ECG: electrocardiogram; EF: ejection fraction; FS: fractional shortening; LVEDD: left ventricle end diastolic dimension; LVESD: left ventricular end systolic dimension; MR: mitral regurgitation.

\section{Introduction}

Cardiomyopathies, accounting for only $1 \%$ of patients with pediatric cardiac diseases, remain a major cause of morbidity and mortality (2). The overall mortality in patients with dilated cardiomyopathy (DCM) has been reported to be as high as $\geq 50 \%(3,4)$. Since the aetiology of DCM is mostly unknown, specific therapy is not possible and so the treatment of DCM is essentially that of congestive heart failure including diuretics, vasodilators and inotropes (5). Many studies on adult patients have suggested that sympathetic activation plays an important role in the genesis and progression of heart failure $(6-8)$, this has led to the addition of 
sympathetic antagonists to the traditional pharmacologic treatments for heart failure in adults. Carvedilol is a third generation non-selective beta-antagonist with alpha adrenergic blocking and anti-oxidant activity (9-13). When combined with diuretics, digoxin and angiotensinconverting enzyme (ACE) inhibitors, carvedilol has been shown to be effective in decreasing hospitalization rates and improving survival in adults with chronic heart failure (CHF) $(6,8,14)$. However, limited information is available about its use in children.

While we report our experience with the use of carvedilol in the pediatric population with cardiomyopathy, this study aims to evaluate its dosing, efficacy as well as safety and tolerability.

\section{Subjects and Methods}

We conducted a prospective, randomized, double-blind, placebo-controlled study. The study included 53 pediatric patients under the age of 14 years with chronic heart failure due to DCM, recruited from the Cardiomyopathy Clinic of Cairo University Children's Hospital (CUCH). The study was approved by the Ethical Committee at Cairo University.

\section{Participants}

All patients with DCM following-up for more than 6 months were screened. Patients with poor response to conventional therapy were included in the study. Poor response was defined as: symptomatic with grade I, II or III heart failure according to the Modified Ross classification (15); with ejection fraction $(\mathrm{EF}) \leq 50 \%$; despite at least two months of treatment with the standard anti-failure treatment (diuretics in sufficient doses to maintain patients free of edema, ACE inhibitors, and digoxin). Patients were excluded if they had active myocarditis, uncontrolled arrhythmia or heart block, systemic arterial hypertension, progressive systemic diseases causing cardiomyopathy, clinically-important hepatic or renal diseases, severe (grade IV) heart failure, hemodynamically-unstable, receiving intravenous inotrope or vasoactive drugs, or were on ventilatory mechanical support.

\section{Methods}

After a baseline evaluation that included detailed history taking, general and cardiac examination, laboratory tests and chest x-ray, echocardiography was performed using a Vivid-5 (GE healthcare, Norway). The following parameters were measured: left ventricular end diastolic dimension (LVEDD), left ventricular end systolic dimension (LVESD), fractional shortening (FS) and ejection fraction (EF). Presence of mitral regurgitation (MR) or intracardiac thrombi were also recorded. Our fifty three children included in this study were randomly assigned (in the ratio of 1:1 to receive carvedilol (group A) or placebo (group B). They underwent a double-blind up-titration phase, in addition to their usual medications:

- Group A included 27 cases, was further subdivided according to the dose of carvedilol into:

- Subgroup I (low-dose carvedilol group) included 11 patients who received an initial dosage of $0.01 \mathrm{mg} / \mathrm{kg} / \mathrm{day}$ of carvedilol for 2 weeks which was then increased (the dosage was double) at two-week intervals first to $0.02 \mathrm{mg} / \mathrm{kg} /$ day, then to $0.04 \mathrm{mg} / \mathrm{kg} /$ day, proceeding in weekly steps to $0.09 \mathrm{mg} / \mathrm{kg} / \mathrm{day}$.

- Subgroup II (high-dose carvedilol group) included 16 cases who received carvedilol with up-titrating its dose every 2 weeks from 0.01 to reach to $0.2 \mathrm{mg} / \mathrm{kg} /$ day in 0.04 step ups over 4 to 5 times. During the up-titration dosage period, patients were evaluated biweekly after which double-blind therapy was maintained for at least an additional four months.

- Group B (control group) included 26 DCM cases who received placebo tablets. During this time, patients were on standard therapy with digoxin, diuretics, and ACE inhibitors. Adjustment in the standard medical therapy was at the discretion of the physicians. After four months of followup, patients were observed for the occurrence of death for cardiovascular reasons, modified Ross functional classification, any reported side effects, decrease in the use of conventional medications and echocardiographic parameters.

\section{Statistical Analysis}

SPSS statistical package version 14 was used to analyze the data. Descriptive data were described in form of frequencies and percentages, mean \pm standard deviation (or median and 
range if data were not normally distributed). Comparisons of values of modified Ross functional classification and echocardiographic assessment between cases and controls were done using Student's t test. Comparison of frequencies among groups were done using Chi square test. A $p$ value of less than 0.05 was considered significant.

\section{Results}

The age at the time of enrollment ranged from 14 months to 5 years (mean 29.12 \pm 20.0 months). Twenty five patients (47\%) were idiopathic, 12 (23\%) were post-myocarditis, 6 (11\%) familial, 5 (9.4\%) were associated with metabolic disease, 2 (3.8\%) with neuromuscular disease, 1 $(1.9 \%)$ with each of: renal failure, collagen vascular disease, and post chemotherapy. There were no significant differences between the 2 groups regarding demographic, clinical, electrocardiogram (ECG) and echocardiographic parameters at the onset of the study (Table 1), also between the subgroups I \& II (Table 2).

Table (I): Baseline characteristics of patients in the study and control groups.

\begin{tabular}{|c|c|c|c|}
\hline & $\begin{array}{c}\text { Carvedilol } \\
\text { (Group A, n=27) } \\
\text { Mean } \pm \text { SD }\end{array}$ & $\begin{array}{c}\text { Placebo } \\
(\text { Group } B, n=26) \\
\text { Mean } \pm \text { SD }\end{array}$ & $\begin{array}{c}\quad P \\
\text { value }\end{array}$ \\
\hline Age (mo) & $29.12 \pm 20.0$ & $36.12 \pm 26.12$ & 0.3 \\
\hline Gender (M/F) & $17 / 10$ & $7 / 19$ & 0.4 \\
\hline Weight (kg) & $12.7 \pm 4.2$ & $13.2 \pm 5.6$ & 0.7 \\
\hline Chest infection episodes no. (\%) & $13(48 \%)$ & $10(39 \%)$ & 0.3 \\
\hline \multicolumn{4}{|c|}{ Ross functional classification } \\
\hline Class I & $7(26 \%)$ & $4(15 \%)$ & \multirow{3}{*}{0.7} \\
\hline Class II & $18(67 \%)$ & $19(73 \%)$ & \\
\hline Class III & $2(7 \%)$ & $3(12 \%)$ & \\
\hline LVEDD (mm) & $43.7 \pm 5.3$ & $43.5 \pm 9.2$ & 0.9 \\
\hline LVESD (mm) & $34.6 \pm 5.2$ & $34.1 \pm 9.5$ & 0.9 \\
\hline Fraction shortening (\%) & $20.2 \pm 3.7$ & $20.0 \pm 8.1$ & 0.9 \\
\hline \multicolumn{4}{|l|}{ Mitral regurgitation (\%) } \\
\hline None & $5(18.5 \%)$ & $2(17 \%)$ & \multirow{5}{*}{0.2} \\
\hline Grade I & $5(18.5 \%)$ & $3(25 \%)$ & \\
\hline Grade II & $10(37 \%)$ & $2(17 \%)$ & \\
\hline Grade III & $6(22 \%)$ & $4(33 \%)$ & \\
\hline Grade IV & $1(4 \%)$ & $1(8 \%)$ & \\
\hline
\end{tabular}

LVEDD: left ventricle end diastolic dimension; LVESD: left ventricular end systolic dimension.

ECG revealed sinus rhythm in all enrolled patients. Sixty percent of the cases had evidence of left ventricular enlargement by voltage criteria; and in six non-specific ST-T changes were present. None of the cases showed abnormal q waves in precordial or limb leads. There were no statistically significant differences of ECG findings between different groups. Chest radiograph showed cardiomegaly in all cases, cardiothoracic ratio ranging from 0.55 to 0.75 (mean $=0.65$ ). Pulmonary congestion was seen in 53\% cases; mild in $20 \%$ and moderate in $33 \%$.

After four months of follow-up, patients were observed for the occurrence of death for cardiovascular reasons, modified Ross functional classification, decrease in the use of conventional medications and echocardiographic parameters. The modified Ross class was used as a direct measure of the clinical progression. No related side effects were reported throughout the study period. In the study group A there was a significant decline in modified Ross class: $63 \%$ of patients with class II at the onset of the study were shifted to class I at the end of the study; $50 \%$ of the patients with class III improved to class I; while only $14 \%$ of patients with class I worsened to class II by end of the study. That improvement in modified Ross classes was statistically-significant compared to the control group (Table 3). Dividing group A to two subgroups showed no significant difference in end-point parameters reached at the end of the study period (Table 4). 
Table 2: Baseline characteristics of patients in subgroups (I) and (II).

\begin{tabular}{|c|c|c|c|}
\hline & $\begin{array}{c}\text { Subgroup I } \\
(n=11) \\
\text { Mean } \pm \text { SD }\end{array}$ & $\begin{array}{c}\text { Subgroup II } \\
(\mathrm{n}=16) \\
\text { Mean } \pm \text { SD }\end{array}$ & $P$ value \\
\hline Age (mo) & $29.12 \pm 15.12$ & $29.12 \pm 23.12$ & 0.9 \\
\hline Gender (M/F) & $6 / 5$ & $11 / 5$ & 0.5 \\
\hline Weight (kg) & $12.8 \pm 3.0$ & $13.4 \pm 4.7$ & 0.3 \\
\hline Chest infection episodes (\%) & $5(45 \%)$ & $8(50 \%)$ & 0.5 \\
\hline \multicolumn{4}{|c|}{ Modified Ross Heart Failure Class } \\
\hline Class I & $2(18 \%)$ & $5(35 \%)$ & \multirow{3}{*}{0.7} \\
\hline Class II & $8(73 \%)$ & $10(63 \%)$ & \\
\hline Class III & $1(9 \%)$ & $1(12 \%)$ & \\
\hline LVEDD (mm) & $45.1 \pm 6.8$ & $42.4 \pm 2.9$ & 0.2 \\
\hline LVESD $(\mathrm{mm})$ & $36.1 \pm 6.5$ & $33.1 \pm 3.0$ & 0.2 \\
\hline Fraction shortening (\%) & $18.5 \pm 3.4$ & $21.3 \pm 3.0$ & 0.06 \\
\hline \multicolumn{4}{|c|}{ Mitral regurgitation no. (\%) } \\
\hline None & 0 & $5(31 \%)$ & \multirow{5}{*}{0.2} \\
\hline Grade I & $3(27 \%)$ & $2(13 \%)$ & \\
\hline Grade II & $4(37 \%)$ & $6(37 \%)$ & \\
\hline Grade III & $3(27 \%)$ & $3(19 \%)$ & \\
\hline Grade IV & $1(9 \%)$ & 0 & \\
\hline
\end{tabular}

LVEDD: left ventricle end diastolic dimension; LVESD: left ventricular end systolic dimension.

Regarding the echocardiographic cardiac functions, there was a significant improvement in patients of the study group A, whereas they deteriorated significantly among patients in the control group B (Figure 1).
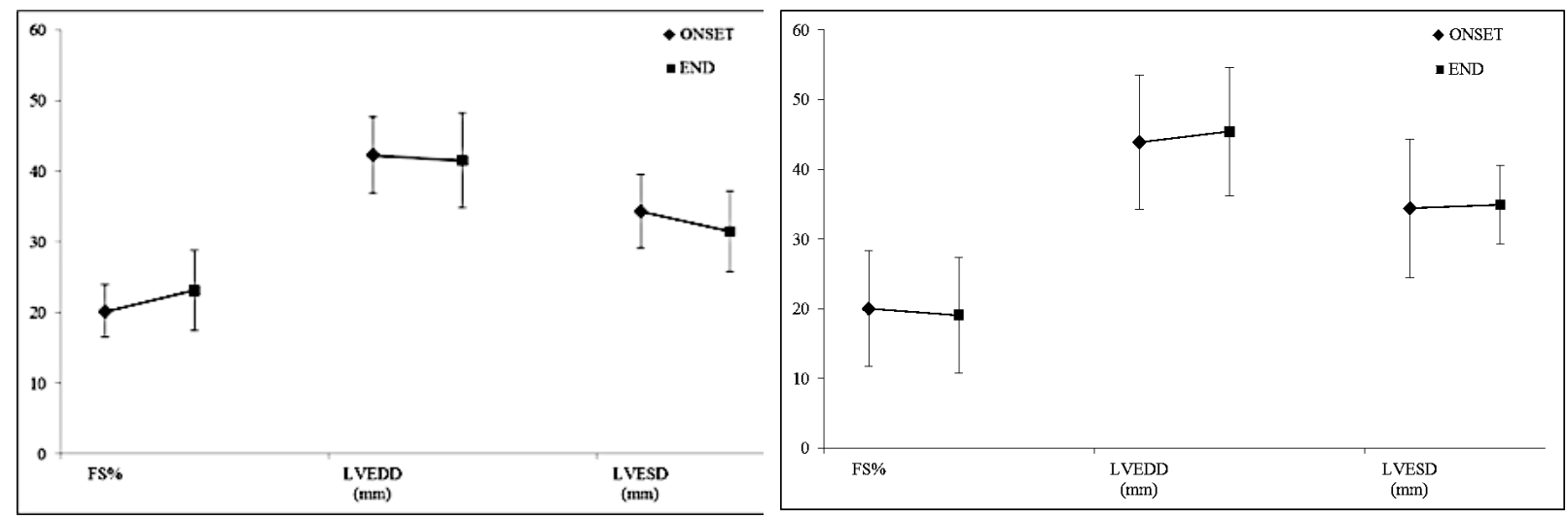

Figure 1: Echocardiographic data of patients in the carvedilol group and in the control group (at the onset and the end of the study).

\section{Discussion}

With advancement in medical therapy, the mortality has declined and quality of life improved in DCM patients. In recent studies, improvement of outcome has been observed on follow up in $45-52 \%$; stationary course in $31-42 \%$ and death in $5-20 \%(4,16)$. Improved survival has been reported in adults with use of spironolactone, ACE inhibitors and beta-blockers $(14,17$ 21); however, in children there is no uniform guideline for the use of beta-blockers in patients with CHF secondary to DCM.

The studies that suggested a possible beneficial effect of beta-blockers are limited by small sample size and lack of randomization (5, 22-26). Whilst a large randomized controlled trial failed to identify clinical effectiveness of carvedilol in children and adolescents with heart failure (27). Carvedilol is a third-generation beta-blocker that has an alpha-blocking action as well, thus causing peripheral vasodilatation (9-13). Carvedilol may have other potential beneficial effects in 
heart failure as anti-oxidant and an anti-proliferative agent (9). We tried in this study to assess prospectively the effects and the tolerability of carvedilol in the treatment of DCM children with $\mathrm{CHF}$ in our Egyptian tertiary care center, and to determine the minimal effective dose.

Table 3: Data of patients included in the study and control groups at the end of the study.

\begin{tabular}{|c|c|c|c|}
\hline Variable & $\begin{array}{c}\text { Carvedilol } \\
\text { Group A (n=27) }\end{array}$ & $\begin{array}{c}\text { Control Group } \\
\text { B }(n=26)\end{array}$ & $P$ value \\
\hline \multicolumn{4}{|c|}{ Modified Ross Heart Failure Class } \\
\hline class I & $19(70 \%)$ & $9(35 \%)$ & \multirow{3}{*}{$0.03^{*}$} \\
\hline class II & $7(26 \%)$ & $13(50 \%)$ & \\
\hline class III & $1(4 \%)$ & $4(15 \%)$ & \\
\hline \multicolumn{4}{|l|}{ Outcome } \\
\hline Improvement & $13(48 \%)$ & $5(19 \%)$ & \multirow{3}{*}{0.07} \\
\hline No change & $13(48 \%)$ & $18(69 \%)$ & \\
\hline Deterioration & $1(4 \%)$ & $3(12 \%)$ & \\
\hline \multicolumn{4}{|c|}{ Mitral regurgitation no. (\%) } \\
\hline & $10(37 \%)$ & $1(8 \%)$ & \multirow{5}{*}{0.2} \\
\hline Grade I & $5(19 \%)$ & $4(33 \%)$ & \\
\hline Grade II & $9(33 \%)$ & $1(8 \%)$ & \\
\hline Grade III & $3(11 \%)$ & $5(42 \%)$ & \\
\hline Grade IV & 0 & $1(8 \%)$ & \\
\hline FS (\%) & $22.7 \pm 6.5$ & $19.1 \pm 8.3$ & $0.04^{*}$ \\
\hline LVEDD (mm) & $41.5 \pm 6.8$ & $45.4 \pm 9.2$ & 0.2 \\
\hline LVESD (mm) & $31.5 \pm 6.7$ & $33.9 \pm 9.6$ & 0.2 \\
\hline
\end{tabular}

FS: Fractional shortening; LVEDD: left ventricle end diastolic dimension; LVESD: left ventricular end systolic dimension.

Table 4: Data of patients included in the subgroups I and II at the end of the study.

\begin{tabular}{|c|c|c|c|}
\hline Variable & $\begin{array}{c}\text { Subgroup I } \\
(\mathrm{n}=11)\end{array}$ & $\begin{array}{c}\text { Subgroup II } \\
(\mathrm{n}=16)\end{array}$ & $P$ value \\
\hline \multicolumn{4}{|c|}{ Modified Ross Heart Failure Class } \\
\hline class I & $6(55 \%)$ & $13(81 \%)$ & \multirow{3}{*}{0.2} \\
\hline class II & $4(36 \%)$ & $3(19 \%)$ & \\
\hline class III & $1(9 \%)$ & 0 & \\
\hline \multicolumn{4}{|l|}{ Outcome } \\
\hline Improvement & $5(45.5 \%)$ & $8(50 \%)$ & \multirow{3}{*}{0.2} \\
\hline No change & $5(45.5 \%)$ & $8(50 \%)$ & \\
\hline Deterioration & $1(9 \%)$ & 0 & \\
\hline \multicolumn{4}{|c|}{ Mitral regurgitation no. (\%) } \\
\hline None & $2(18 \%)$ & $8(50 \%)$ & \multirow{5}{*}{0.5} \\
\hline Grade I & $2(18 \%)$ & $3(19 \%)$ & \\
\hline Grade II & $4(36 \%)$ & $5(31 \%)$ & \\
\hline Grade III & $3(28 \%)$ & 0 & \\
\hline Grade IV & 0 & $1(8 \%)$ & \\
\hline FS (\%) & $19.8 \pm 7.3$ & $24.7 \pm 5.2$ & 0.08 \\
\hline LVEDD (mm) & $42.3 \pm 8.7$ & $40.7 \pm 4.3$ & 0.6 \\
\hline LVESD (mm) & $32.9 \pm 7.0$ & $30.2 \pm 4.0$ & 0.3 \\
\hline
\end{tabular}

FS: Fractional shortening; LVEDD: left ventricle end diastolic dimension; LVESD: left ventricular end systolic dimension.

During a treatment period of 4 months after reaching target dose, patients with mildmoderate $\mathrm{CHF}$ in the carvedilol group were more likely to show symptomatic improvement and 
were less likely to experience clinical deterioration than patients in the placebo group. In their study, Bajcetic and colleagues study on children with idiopathic DCM also reported a significant improvement in modified Ross class in $80 \%$ of children $(\mathrm{p}<0.001)$ at 12 months $(28)$. Our results agree with most of other reports in the literature but most of these had a small sample size with lack of randomization; only two were only two placebo-controlled studies. Most of these reports showed improvement in Ross class and ejection fraction compared to untreated controls, that trended toward delaying time to transplant or death $(24-26,29)$.

We show that adding carvedilol to the traditional anti-failure therapy is beneficial not only in the functional classification, but the echocardiographic parameters as well. Our study group had significant reduction in LVEDD ( $p=0.0001)$; in LVESD $(\mathrm{p}=0.0001)$ and a significant increase in FS ( $p=0.002)$. These results are similar to a couple of studies carried out in last decade by Maunoury et al. (30) and Gerson et al. (31). Saucedu and colleagues also showed significant improvement in the FS\% to the extent that the myocardial performance index was normalized in five patients at the end of the 8 months follow-up period (32). Gardini et al. proposes the beneficial in ventricular function and clinical condition through modulation of the neurohormonal activity which led to a significant reduction in LVEDD $(p=0.004)$ and LVESD $(p=0.009)$ and a significant increase in the FS ( $\mathrm{p}=0.001)$ (33).

We compare our results with two other placebo-controlled studies: Azeka et al. (24) studied a total of 22 children with severe left ventricular dysfunction listed for cardiac transplantation (8 placebo patients and 14 patients received carvedilol at $0.01 \mathrm{mg} / \mathrm{kg} /$ day titrated up to $0.2 \mathrm{mg} / \mathrm{kg} /$ day) that were followed-up for six months, showed significant benefit of using carvedilol; while the very well-designed randomized control study by Shaddy et al (27) ended with results that oppose our study: they failed to show beneficial effect on a heterogeneous group of children and adolescents with CHF (including 95 with DCM and 66 with and congenital heart disease). However, a subgroup analysis indicated a differential effect were a beneficial trend in patients with a systemic $\mathrm{LV}(\mathrm{p}=0.02)$ in contrast to a non-beneficial trend in patients where the LV was not the systemic ventricle, thus there may be a differential effect of carvedilol based on ventricular morphology.

Functional mitral regurgitation, caused by papillary dysfunction, is a poor prognostic marker in the setting of heart failure $(34,35)$. We found that severity of mitral regurgitation in the carvedilol group decreased from entry point to end of follow-up in comparison to placebo group; in five cases mitral regurgitation disappeared completely in the carvedilol group. This improvement in severity of mitral regurgitation has been described in a retrospective study by Saxena et al. which included 33 DCM patients with moderate to severe ventricular dysfunction (29).

It was previously thought that the efficacy and benefits of beta-blockade could not be obtained during the first several weeks of treatment. That old thought was disapproved by a study done by Krum et al which proved that carvedilol challenged that belief during both initiation and up-titration periods. Patients treated with carvedilol in that study did not show increased risk of worsening CHF, pulmonary edema, cardiogenic shock or other serious cardiovascular events including death (36). We similarly show in our present study that carvedilol benefits are obtained from the first few weeks with no remarkable adverse effects during the initiation and up-titration period of carvedilol therapy. The dose of carvedilol and the way of its up-titration that we followed among the cases of the subgroup II is similar to which is used by Azeka and colleagues (24). The period of follow-up in our study was 4 months: we report no adverse effects noted in these patients that necessitated discontinuation of carvedilol therapy at any point, but rather progressive clinical improvement was noted in this subgroup of patients during the period of up-titration.

Our study advocates that up-titration of carvedilol dose is not necessary in the pediatric age, at least during the initial months of treatment, based on similar clinical and echocardiographic outcomes for the two subgroups I and II (33). This was disapproved by the study of Bristow that reported a dose-related improvement in LV function and survival in adult patients (37). We also debate with the more recent work by Sexana and colleges where carvedilol was started at a low initial dose of $0.1-0.2 \mathrm{mg} / \mathrm{kg} / \mathrm{d}$ (mean $0.14 \pm 0.03 \mathrm{mg} / \mathrm{kg} / \mathrm{d}$ ), up-titrated to a final maintenance dose of $0.3-0.6 \mathrm{mg} / \mathrm{kg} / \mathrm{d}$ (mean $0.46 \pm 0.14 \mathrm{mg} / \mathrm{kg} / \mathrm{d}$ ), and concluded that therapy with carvedilol is best initiated in small doses and very slowly titrated over several weeks to the maximum tolerated dose (29). 
This study was limited by the relatively short-term period of follow-up, longer follow-up could infer more about optimum dosing and the potential benefit in survival. Also the number of candidates did not allow the break-down of subgroups according to the etiology or duration of cardiomyopathy.

\section{Conclusion}

Carvedilol is beneficial in symptomatic and functional improvement of pediatric patients with heart failure due to cardiomyopathy, when added to the regular antifailure medications. Uptitrating the dose is equally effective to the low-dose treatment.

Author Contributions: All authors searched medical literature, databases, conceptualized, conducted the case review and reviewed the final manuscript. All authors have read and agreed to the published version of the manuscript.

\section{FUNDING}

Authors declare there was no extramural funding provided for this study.

\section{CONFLICT OF INTEREST}

The authors declare no conflict of interest in connection with the reported study. Authors declare veracity of information.

\section{References}

1. S. Tenny, M. Varacallo, Evidence Based Medicine. (StatPearls Publishing; Treasure Island (FL), 2020; https://www.ncbi.nlm.nih.gov/books/NBK470182/).

2. M. A. Grenier, S. K. Osganian, G. F. Cox, J. A. Towbin, S. D. Colan, P. R. Lurie, L. A. Sleeper, E. J. Orav, S. E. Lipshultz, Design and implementation of the North American Pediatric Cardiomyopathy Registry. Am. Heart J. 139, s86-s95 (2000).

3. A. Arola, J. Tuominen, O. Ruuskanen, E. Jokinen, Idiopathic Dilated Cardiomyopathy in Children: Prognostic Indicators and Outcome. Pediatrics. 101, 369-376 (1998).

4. I. Saad, Idiopathic Dilated Cardiomyopathy in Children: Natural History and Predictors of Prognosis. Libyan J. Med. 2, 129-134 (2007).

5. L. A. Bruns, M. K. Chrisant, J. M. Lamour, R. E. Shaddy, E. Pahl, E. D. Blume, S. Hallowell, L. J. Addonizio, C. E. Canter, Carvedilol as therapy in pediatric heart failure: An initial multicenter experience. J. Pediatr. 138, 505-511 (2001).

6. M. Packer, M. R. Bristow, J. N. Cohn, W. S. Colucci, M. B. Fowler, E. M. Gilbert, N. H. Shusterman, The Effect of Carvedilol on Morbidity and Mortality in Patients with Chronic Heart Failure. N. Engl. J. Med. 334, 1349-1355 (1996).

7. R. N. Doughty, G. A. Whalley, G. Gamble, S. MacMahon, N. Sharpe, Left Ventricular Remodeling With Carvedilol in Patients With Congestive Heart Failure Due to Ischemic Heart Disease fn1fn1This study was funded by a grant from SmithKline Beecham; however, the study was initiated, conducted, analyzed and reported by the Australia-New Zealand Heart Failure Research Collaborative Group independently of the sponsor. The Clinical Trials Research Unit is supported by a programme grant from the Health Research Council of New Zealand. J. Am. Coll. Cardiol. 29, 1060-1066 (1997).

8. W. S. Colucci, M. Packer, M. R. Bristow, E. M. Gilbert, J. N. Cohn, M. B. Fowler, S. K. Krueger, R. Hershberger, B. F. Uretsky, J. A. Bowers, J. D. Sackner-Bernstein, S. T. Young, T. L. Holcslaw, M. A. Lukas, Carvedilol Inhibits Clinical Progression in Patients With Mild Symptoms of Heart Failure. Circulation. 94, 2800-2806 (1996).

9. T. Morgan, Clinical Pharmacokinetics and Pharmacodynamics of Carvedilol: Clin. Pharmacokinet. 26, 335-346 (1994).

10. G. Jonsson, M. Abdelnoor, C. Müller, S. E. Kjeldsen, I. Os, A. Westheim, A Comparison of the Two B-Blockers Carvedilol and Atenolol on Left Ventricular Ejection Fraction and Clinical Endpoints after Myocardial Infarction. Cardiology. 103, 148-155 (2005).

11. T. Yoshikawa, J. D. Port, K. Asano, P. Chidiak, M. Bouvier, D. Dutcher, R. L. Roden, W. Minobe, K. D. Tremmel, M. R. Bristow, Cardiac adrenergic receptor effects of carvedilol. Eur. Heart J. 17, 8-16 (1996). 
12. T. L. Yue, H. Y. Cheng, P. G. Lysko, P. J. McKenna, R. Feuerstein, J. L. Gu, K. A. Lysko, L. L. Davis, G. Feuerstein, Carvedilol, a new vasodilator and beta adrenoceptor antagonist, is an antioxidant and free radical scavenger. J. Pharmacol. Exp. Ther. 263, 92-98 (1992).

13. G. Z. Feuerstein, R. R. Ruffolo, Carvedilol, a novel vasodilating beta-blocker with the potential for cardiovascular organ protection. Eur. Heart J. 17, 24-29 (1996).

14. M. Packer, W. S. Colucci, J. D. Sackner-Bernstein, C. Liang, D. A. Goldscher, I. Freeman, M. L. Kukin, V. Kinhal, J. E. Udelson, M. Klapholz, S. S. Gottlieb, D. Pearle, R. J. Cody, J. J. Gregory, N. E. Kantrowitz, T. H. LeJemtel, S. T. Young, M. A. Lukas, N. H. Shusterman, Double-Blind, Placebo-Controlled Study of the Effects of Carvedilol in Patients With Moderate to Severe Heart Failure: The PRECISE Trial. Circulation. 94, 2793-2799 (1996).

15. R. D. Ross, The Ross Classification for Heart Failure in Children After 25 Years: A Review and an Age-Stratified Revision. Pediatr. Cardiol. 33, 1295-1300 (2012).

16. BOSTAN, Ölem M., CIL, Ergun, Dilated cardiomyopathy in childhood. Acta Cardiol., 169174 (2006).

17. Å. Hjalmarson, S. Goldstein, B. Fagerberg, H. Wedel, F. Waagstein, J. Kjekshus, J. Wikstrand, D. El Allaf, J. Vítovec, J. Aldershvile, M. Halinen, R. Dietz, K.-L. Neuhaus, A. Jánosi, G. Thorgeirsson, P. H. J. M. Dunselman, L. Gullestad, J. Kuch, J. Herlitz, P. Rickenbacher, S. Ball, S. Gottlieb, P. Deedwania, for the MERIT-HF Study Group, Effects of Controlled-Release Metoprolol on Total Mortality, Hospitalizations, and Well-being in Patients With Heart Failure: The Metoprolol CR/XL Randomized Intervention Trial in Congestive Heart Failure (MERIT-HF). JAMA. 283, 1295 (2000).

18. E. J. Eichhorn, M. R. Bristow, The Carvedilol Prospective Randomized Cumulative Survival (COPERNICUS) trial. Curr. Control. Trials Cardiovasc. Med. 2, 20 (2001).

19. B. Pitt, F. Zannad, W. J. Remme, R. Cody, A. Castaigne, A. Perez, J. Palensky, J. Wittes, The Effect of Spironolactone on Morbidity and Mortality in Patients with Severe Heart Failure. N. Engl. J. Med. 341, 709-717 (1999).

20. The Consensus Trial Study Group*, Effects of Enalapril on Mortality in Severe Congestive Heart Failure. N. Engl. J. Med. 316, 1429-1435 (1987).

21. The SOLVD Investigators*, Effect of Enalapril on Survival in Patients with Reduced Left Ventricular Ejection Fractions and Congestive Heart Failure. N. Engl. J. Med. 325, 293302 (1991).

22. R. E. Shaddy, S. L. Olsen, M. R. Bristow, D. O. Taylor, E. A. Bullock, L. Y. Tani, D. G. Renlund, Efficacy and safety of metoprolol in the treatment of doxorubicin-induced cardiomyopathy in pediatric patients. Am. Heart J. 129, 197-199 (1995).

23. R. E. Shaddy, L. Y. Tani, S. S. Gidding, E. Pahl, G. S. Orsmond, E. M. Gilbert, V. Lemes, Beta-blocker treatment of dilated cardiomyopathy with congestive heart failure in children: a multi-institutional experience. J. Heart Lung Transplant. 18, 269-274 (1999).

24. E. Azeka, J. A. Franchini Ramires, C. Valler, E. Alcides Bocchi, Delisting of infants and children from the heart transplantation waiting list after carvedilol treatment. J. Am. Coll. Cardiol. 40, 2034-2038 (2002).

25. P. Rusconi, O. Gómez-Marín, M. Rossique-González, E. Redha, J. R. Marín, M. Lon-Young, G. S. Wolff, Carvedilol in children with cardiomyopathy: 3-year experience at a single institution. J. Heart Lung Transplant. 23, 832-838 (2004).

26. E. D. Blume, C. E. Canter, R. Spicer, K. Gauvreau, S. Colan, K. J. Jenkins, Prospective Single-Arm Protocol of Carvedilol in Children with Ventricular Dysfunction. Pediatr. Cardiol. 27, 336-342 (2006).

27. R. E. Shaddy, M. M. Boucek, D. T. Hsu, R. J. Boucek, C. E. Canter, L. Mahony, R. D. Ross, E. Pahl, E. D. Blume, D. A. Dodd, D. N. Rosenthal, J. Burr, B. LaSalle, R. Holubkov, M. A. Lukas, L. Y. Tani, F. the Pediatric Carvedilol Study Group, Carvedilol for Children and Adolescents With Heart Failure: A Randomized Controlled Trial. JAMA. 298, 1171 (2007).

28. M. Bajcetic, A. Nikolic Kokic, M. Djukic, J. Kosutic, J. Mitrovic, D. Mijalkovic, I. Jovanovic, S. Simeunovic, M. B. Spasic, R. Samardzic, Effects of Carvedilol on Left Ventricular Function and Oxidative Stress in Infants and Children with Idiopathic Dilated Cardiomyopathy: A 12-Month, Two-Center, Open-Label Study. Clin. Ther. 30, 702-714 (2008).

29. A. Saxena, O. M. Anil, R. Juneja, Clinical and Echocardiographic Outcome in Patients Receiving Carvedilol for Treatment of Dilated Cardiomyopathy. Indian J. Pediatr. 80, 549554 (2013). 
30. C. Maunoury, P. Acar, D. Sidi, Use of 123 I-MIBG scintigraphy to assess the impact of carvedilol on cardiac adrenergic neuronal function in childhood dilated cardiomyopathy. Eur. J. Nucl. Med. Mol. Imaging. 30, 1651-1656 (2003).

31. M. Gerson, Carvedilol improves left ventricular function in heart failure patients with idiopathic dilated cardiomyopathy and a wide range of sympathetic nervous system function as measured by iodine 123 metaiodobenzylguanidine. J. Nucl. Cardiol. 9, 608-615 (2002).

32. N. A. B. Saucedo, A. V. Alarcón, G. E. Islas, L. R. De La Cruz, [Evaluation of the effect of carvedilol in children with dilated cardiomyopathy]. Arch. Cardiol. Mex. 78, 52-59 (2008).

33. A. Giardini, R. Formigari, G. Bronzetti, D. Prandstraller, A. Donti, M. Bonvicini, F. M. Picchio, Modulation of neurohormonal activity after treatment of children in heart failure with carvedilol. Cardiol. Young. 13, 333-336 (2003).

34. F. Praz, C. Grasso, M. Taramasso, A. Baumbach, N. Piazza, C. Tamburino, S. Windecker, F. Maisano, B. Prendergast, Mitral regurgitation in heart failure: time for a rethink. Eur. Heart J. 40, 2189-2193 (2019).

35. G. Goliasch, P. E. Bartko, N. Pavo, S. Neuhold, R. Wurm, J. Mascherbauer, I. M. Lang, G. Strunk, M. Hülsmann, Refining the prognostic impact of functional mitral regurgitation in chronic heart failure. Eur. Heart J. 39, 39-46 (2018).

36. H. Krum, E. B. Roecker, P. Mohacsi, J. L. Rouleau, M. Tendera, A. J. S. Coats, H. A. Katus, M. B. Fowler, M. Packer, for the Carvedilol Prospective Randomized Cumulative Survival (COPERNICUS) Study Group, Effects of Initiating Carvedilol in Patients With Severe Chronic Heart Failure: Results From the COPERNICUS Study. JAMA. 289, 712 (2003).

37. M. R. Bristow, E. M. Gilbert, W. T. Abraham, K. F. Adams, M. B. Fowler, R. E. Hershberger, S. H. Kubo, K. A. Narahara, H. Ingersoll, S. Krueger, S. Young, N. Shusterman, Carvedilol Produces Dose-Related Improvements in Left Ventricular Function and Survival in Subjects With Chronic Heart Failure. Circulation. 94, 2807-2816 (1996).

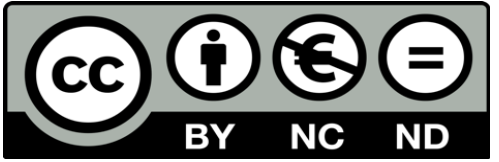

(C) 2021 submitted by the authors. Open access publication under the terms and conditions of the Creative Commons Attribution (CC- BYNC- ND) license. (https://creativecommons.org/licenses/by-nc-nd/2.0/). 